\title{
Effect of Rotor Thrust on the Average Tower Drag of Downwind Turbines
}

\author{
Shigeo Yoshida ${ }^{1, *(\mathbb{D}, \text { Kazuyuki Fujii }}{ }^{2}$, Masahiro Hamasaki ${ }^{1}$ and Ao Takada ${ }^{1}$ \\ 1 Research Institute for Applied Mechanics, Kyushu University, 6-1 Kasugakoen, Kasuga, Fukuoka 816-8580, \\ Japan; hamasaki@riam.kyushu-u.ac.jp (M.H.); takada@riam.kyushu-u.ac.jp (A.T.) \\ 2 Interdisciplinary Graduate School of Engineering and Science, Kyushu University, 6-1 Kasugakoen, Kasuga, \\ Fukuoka 816-8580, Japan; fujiik@riam.kyushu-u.ac.jp \\ * Correspondence: yoshidas@riam.kyushu-u.ac.jp; Tel. +81-92-583-7747
}

Received: 28 November 2018; Accepted: 8 January 2019; Published: 12 January 2019

check for updates

\begin{abstract}
A new analysis method to calculate the rotor-induced average tower drag of downwind turbines in the blade element momentum (BEM) method was developed in this study. The method involves two parts: calculation of the wind speed distribution using computational fluid dynamics, with the rotor modeled as a uniform loaded actuator disc, and calculation of the tower drag via the strip theory. The latter calculation considers two parameters, that is, the decrease in wind speed and the pressure gradient caused by the rotor thrust. The present method was validated by a wind tunnel test. Unlike the former BEM, which assumes the tower drag to be constant, the results obtained by the proposed method demonstrate much better agreement with the results of the wind tunnel test, with an accuracy of $30 \%$.
\end{abstract}

Keywords: wind turbine; downwind; tower shadow; load; tower; BEM; actuator disc

\section{Introduction}

Horizontal axis wind turbines are categorized as upwind and downwind turbines according to the position of the rotor relative to the tower. Among these, upwind turbines have been predominant throughout the 30 year history of commercial wind turbines. The most essential reason for the unpopularity of the downwind turbines is the presence of a strong aerodynamic interaction between the rotor and the tower, which is commonly known as the "tower shadow effect". This phenomenon generates impulsive loads and infrasound when one of the blades passes through the wake of the tower [1]. The modeling of the tower shadow effect is a critical technical problem of downwind turbines.

Design loads are calculated on the basis of the international design standard IEC61400-1 [2] or the guidelines for certification bodies DNV GL [3]. In a large number of cases in which the design load is combined with the wind model, the wind turbines can experience failure conditions, as well as various types of wind and marine conditions. The flexibilities of the structure and the controls, in addition to the aerodynamics, hydrodynamics, aero-elastics, and control of the wind turbines, considerably influence the load. The blade element momentum (BEM) method is the most popular tool for determining these characteristics [4,5]. Therefore, the modeling of the tower shadow effect in the $\mathrm{BEM}$ is one of the most important technical challenges in the design and development of downwind wind turbines. However, most of the tower shadow models are too simple to express such phenomena, as they consider only the wind speed profile behind an isolated tower $[5,6]$ and not the aerodynamic interaction between the rotor and the tower.

Several studies have been conducted until now that have focused on the variable loads of the downwind turbines caused by the tower shadow effect. Zhao et al. [7] studied the loads on a tower 
by performing a comparison between two- and three-bladed upwind and downwind rotors in two different rotor speed conditions using computational fluid dynamics (CFD). The peak to average values of the hub bending moment and the tower base bending moment of the downwind turbine were shown to be 5-6 times and 2.5 times larger, respectively, than those of the upwind turbine. Zahle et al. [8] conducted 2-dimensional CFD analysis for three typical tower concepts of downwind turbines as well as for an upwind turbine; a steep load variation was noted for the downwind turbine, and the implementation of streamlined and four-leg towers was shown to be an effective technique to reduce the load variation caused by the tower shadow effects. Matiz-Chicacausa and Lopez [9] investigated the possibilities of the application of the actuator line model (ALM) to the CFD analysis of the tower shadow effects. The ALM was shown to be useful for load estimation of a downwind turbine under specific conditions.

Although the abovementioned research contributed to the expansion of the understanding of the phenomenon, the authors did not aim to develop models for extensive load calculations based on the design standards and guidelines. Wang and Coton [10] developed a high-resolution tower shadow model for downwind turbines based on the prescribed wake vortex model and an efficient near wake dynamics model of the vorticity trailing the blades. The model demonstrated reasonable agreement with the experimental results, with the exception of the blades passing through the tower wake. However, the load of the tower was not discussed in this research. Yoshida and Kiyoki [11,12] developed the load equivalent tower shadow modeling method. The method considered a bell-shaped wind speed profile behind the tower, which helped obtain the equivalent rotor load variation with the wind turbine CFD analysis. This model was applied to the development of the first multimegawatt-scale commercial downwind turbines, including the SUBARU 80/20 [13] and, later, the Hitachi $2 \mathrm{MW}$, to realize high performance and safety in complex terrains $[14,15]$. The technology was extended to the later produced Hitachi 5 MW [16] offshore wind turbines. The model has been successfully applied in engineering applications so far; however, two major problems remained unsolved. The first concern was that the CFD modeling of the rotor-tower configuration required for each operating condition was time-consuming, which made the technique inconvenient for use in the design optimization process. The second issue was that no model was established for the tower shadow effects on the tower drag. Considering the situation, the tower load variation caused by the tower shadow effect was modeled by Yoshida by combining the BEM and the Lifting Line Theory [17]. However, the average tower drag was still not discussed in that research.

Considering these situations, this paper proposes a BEM model for the tower average drag. The formulation is presented in Section 2, and the validation of the method by a wind tunnel test is discussed in Sections 3-5.

\section{Methodology}

The formulation of the average loads of the towers of the downwind turbine by using the BEM is discussed in this chapter. The following two calculations are considered:

(1) Wind speed distribution by CFD

(2) Rotor thrust-induced tower average drag

\subsection{Wind Speed Distribution by CFD}

The wind speed distribution in front of the rotor is calculated using CFD. Figure 1 shows the top view of the rotor and the tower of a downwind turbine. The tower, which has the diameter $D_{T}$, is located in front of the rotor. The free stream wind speed $U_{0}$ decreases to $U_{0}(1-a)$ at the rotor plane as a result of the rotor thrust. Here, $a$ is the axial induction factor. Figure 2 is the schematic of the CFD involved in the present study. The tower is not included in the model, but the position is termed "virtual tower position" in this research. Further, $u_{T}$ is the wind speed at the virtual tower position, which is between $U_{0}$ and $U_{0}(1-a)$, depending on the condition. The rotor is modeled by an actuator 
disc model (ADM). The load distribution is assumed to be uniform to realize a convenient application to the BEM. The thrust per unit volume $\sigma$ of the ADM is as shown in Equation (1):

$$
\sigma=\frac{1}{2 \pi r w} \frac{d T}{d r}
$$

where $w$ is the thickness of the ADM.
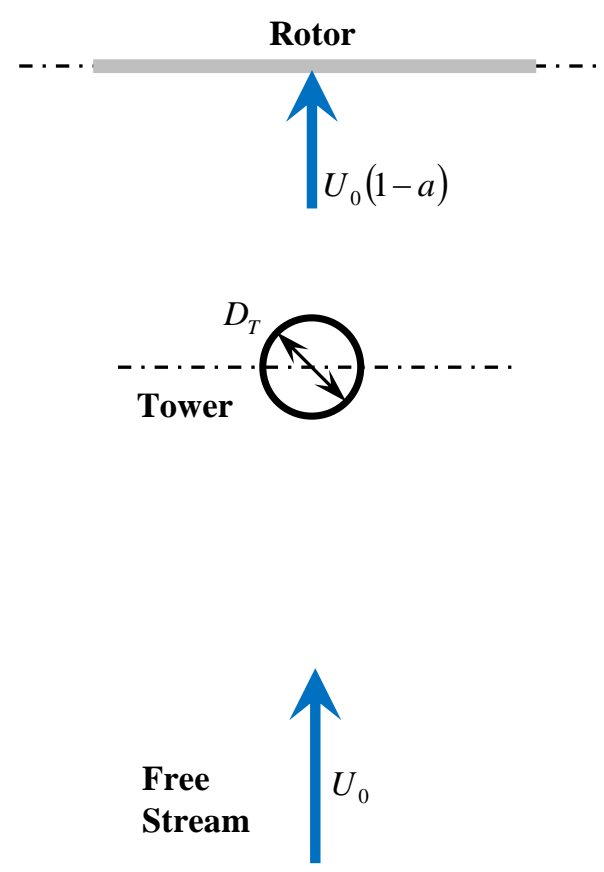

Figure 1. Top view of a downwind turbine. $U_{0}$, free stream wind speed, $D_{T}$, tower diameter.
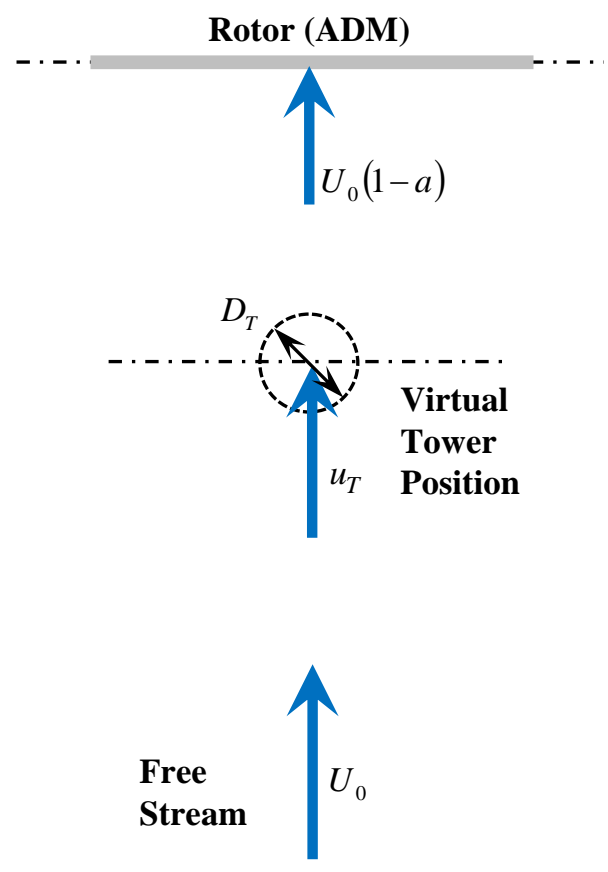

Figure 2. Computational fluid dynamics (CFD) with actuator disc model (ADM). $u_{T}$, wind speed at the virtual tower position. 


\subsection{Rotor Thrust-Induced Tower Average Drag}

The wind speed at the tower and the tower drag decrease as the rotor thrust increases due to the aerodynamic interaction. Two factors, that is, the wind speed and the ambient pressure gradient caused by the rotor thrust, are considered in this research. The formulation is based on the assumption of the strip theory, according to which the flow between the sections normal to the tower axis is not taken into account.

(1) Wind Speed Effect

The tower drag decreases proportionally to the square of the wind speed when the tower section drag coefficient remains constant. This influence is modeled herein.

The section drag $f_{\text {ХTO }}$ of the isolated tower with no rotor interaction is as shown in Equation (2):

$$
f_{X T 0}=\frac{1}{2} \rho U_{0}^{2} D_{T} C_{d T 0}
$$

where $C_{d T 0}$ is the drag coefficient at the tower section.

In case the effect of the rotor thrust comes into play, the wind speed at the tower position decreases. Furthermore, the tower section drag also decreases from $f_{X T 0}$ to $f_{X T}$. This is expressed in the following two ways, based on the wind speeds at the free stream and at the virtual tower position, as shown in Equation (3):

$$
f_{X T}=\frac{1}{2} \rho U_{0}^{2} D_{T} C_{d T}=\frac{1}{2} \rho u_{T}^{2} D_{T} C_{d T 0}
$$

where $C_{d T}$ is the tower section drag based on the free stream wind speed, and $u_{T}$ is the wind speed at the virtual tower position, which is calculated by CFD without incorporating a tower model, as explained in the previous section. Here, the drag coefficient $C_{d T 0}$ is assumed to be constant as in Equation (2).

Therefore, the tower section drag deviation induced by the rotor thrust $\Delta f_{X T}$ is calculated as in Equation (4):

$$
\Delta f_{X T V}=f_{X T}-f_{X T 0}=-\frac{1}{2} \rho U_{0}^{2} D_{T} C_{d T 0}\left(1-\mu_{T}^{2}\right)
$$

where the normalized wind speed at the virtual tower is

$$
\mu_{T}=\frac{u_{T}}{U_{0}}
$$

Therefore, the change in the relevant drag coefficient caused by the wind speed change $\Delta C_{d T V}$ is calculated by Equation (4), as given in Equation (5):

$$
\Delta C_{d T V}=-C_{d T 0}\left(1-\mu_{T}^{2}\right)
$$

This indicates that the term of the tower section drag decreases as the normalized wind speed at the virtual tower, induced by the rotor thrust, decreases.

(2) Effect of the Ambient Pressure Gradient

The tower drag is also dependent on the ambient pressure gradient around the tower. This influence is modeled herein.

The pressure at the virtual tower position $p_{T}$ is calculated by Bernoulli's law, as in Equation (4):

$$
p_{0}+\frac{1}{2} \rho u_{0}^{2}=p_{T}+\frac{1}{2} \rho u_{T}^{2}
$$


where $p_{0}$ and $p_{T}$ are the pressures at the free stream and the virtual tower center, respectively. Therefore, the windward pressure gradient $\partial p_{T} / \partial x_{T}$ at the virtual tower center is calculated as shown in Equation (5) by the differential of Equation (4):

$$
\frac{\partial p_{T}}{\partial x_{T}}=-\rho u_{T} \frac{\partial u_{T}}{\partial x_{T}}
$$

The section drag by the pressure gradient at the tower section $\Delta f_{X T P}$ is calculated as in Equation (6) by employing the pressure deviation from the front and back sides of the tower and the tower diameter. The pressure deviation is calculated by the pressure gradient and the windward reference distance $\Delta x_{T}$ :

$$
\Delta f_{\mathrm{XTP}}=\frac{\partial p_{T}}{\partial x_{T}} \Delta x_{T} D_{T}
$$

Assuming a uniform pressure gradient, the tower section drag is expressed as in Equation (7):

$$
\Delta f_{X T P}=\int_{-\pi / 2}^{\pi / 2}\left(\frac{\partial p_{T}}{\partial x_{T}} D_{T} \cos \phi_{T}\right)\left(\frac{D_{T}}{2} \cos \phi_{T}\right) d \phi_{T}
$$

The reference distance is calculated as in Equation (8) using Equations (6) and (7):

$$
\Delta x_{T}=\frac{\pi}{4} D_{T}
$$

Therefore, the change in the tower section drag owing to the pressure gradient is calculated as in Equation (9):

$$
\Delta f_{X T P}=\frac{\pi D_{T}^{2} \rho u_{T}}{4} \frac{\partial u_{T}}{\partial x_{T}}=\frac{\pi D_{T} \rho U_{0}^{2} \mu_{T}}{4} \frac{\partial \mu_{T}}{\partial \xi_{T}}
$$

where $\xi_{T}$ is the normalized distance and can be written as

$$
\xi_{T}=\frac{x_{T}}{D_{T}}
$$

Therefore, the change in the relevant drag coefficient caused by the pressure gradient $\Delta C_{d T P}$ can be written as in Equation (10):

$$
\Delta C_{d T P}=\frac{\pi}{2} \mu_{T} \frac{\partial \mu_{T}}{\partial \xi_{T}}
$$

This indicates that the term of the tower section drag decreases as the negative pressure gradient caused by the rotor thrust increases.

(3) Total Average Tower Drag

From (1) and (2), the deviation of the drag $\Delta f_{X T}$ and the drag coefficient $\Delta C_{d T}$ induced by the rotor thrust are derived as Equations (11) and (12), respectively:

$$
\begin{gathered}
\Delta f_{X T}=\Delta f_{X T V}+\Delta f_{X T P}=\frac{1}{2} \rho U_{0}^{2} D_{T}\left[-C_{d T 0}\left(1-\mu_{T}^{2}\right)+\frac{\pi}{2} \mu_{T} \frac{\partial \mu_{T}}{\partial \xi_{T}}\right] \\
\Delta C_{d T}=\Delta C_{d T V}+\Delta C_{d T P}=-C_{d T 0}\left(1-\mu_{T}^{2}\right)+\frac{\pi}{2} \mu_{T} \frac{\partial \mu_{T}}{\partial \xi_{T}}
\end{gathered}
$$

\section{Wind Tunnel Test}

\subsection{Outline}

A wind tunnel test for a wind turbine was conducted to validate the theory described in the previous chapter. The rotor-tower interaction was simulated by a dummy tower placed in front of the rotor of the upwind turbine. 


\subsection{Facility}

The Boundary Layer Wind Tunnel at the Research Institute for Applied Mechanics, Kyushu University [18], was used for the test. The wind tunnel has a test section with a width of $3.6 \mathrm{~m}$, a height of $2.0 \mathrm{~m}$, and a length of $15 \mathrm{~m}$. The maximum wind speed is $30 \mathrm{~m} / \mathrm{s}$.

\subsection{Test Model}

The general specifications and the outline of the model and the tower installed in the wind tunnel are presented in Table 1. The blockage ratio, which is the ratio of the rotor area to the cross section of the wind tunnel, is as small as $5.3 \%$. The rotor speed is controlled by the variable dump load. Figure 3 shows the schematic of the test model and the dummy tower. Although the model is an upwind turbine supported by a tower with a diameter of $50.8 \mathrm{~mm}$, a dummy tower is installed in front of the model to mimic the downwind turbine tower. The diameter of the dummy tower is $64 \mathrm{~mm}$, which is $200 \%$ the value of the blade chord length. The dummy tower was placed at two positions; $-6 D_{T}$ and $-4 D_{T}$. Figure 4 shows an image of the test model. The dummy tower is shown as located in front of the turbine.

Table 1. Specifications of the test model and the dummy tower.

\begin{tabular}{cc}
\hline Item & Specification \\
\hline Number of blades & 2 \\
Rotor diameter $D$ & $700 \mathrm{~mm}$ \\
Rotor radius $R$ & $350 \mathrm{~mm}$ \\
Tilt angle & $0 \mathrm{deg}$ \\
Coning angles & $0 \mathrm{deg}$ \\
Airfoil & NACA0013 \\
Blade chord length & $32 \mathrm{~mm}$ \\
Twist angle & $0 \mathrm{deg}$ \\
Tower diameter $D_{T}$ & $64 \mathrm{~mm}$ \\
\hline Tower position & $-338 \mathrm{~mm}\left(-6 D_{T}\right)$ \\
\hline
\end{tabular}

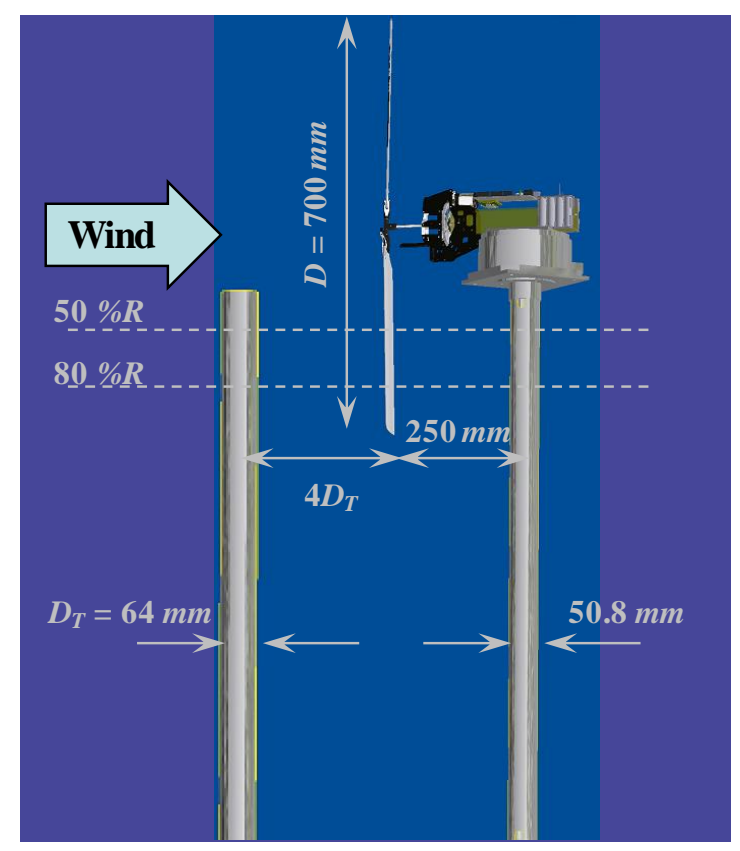

Figure 3. Schematic of the test model (dummy tower at $-4 D_{T}$ ). 


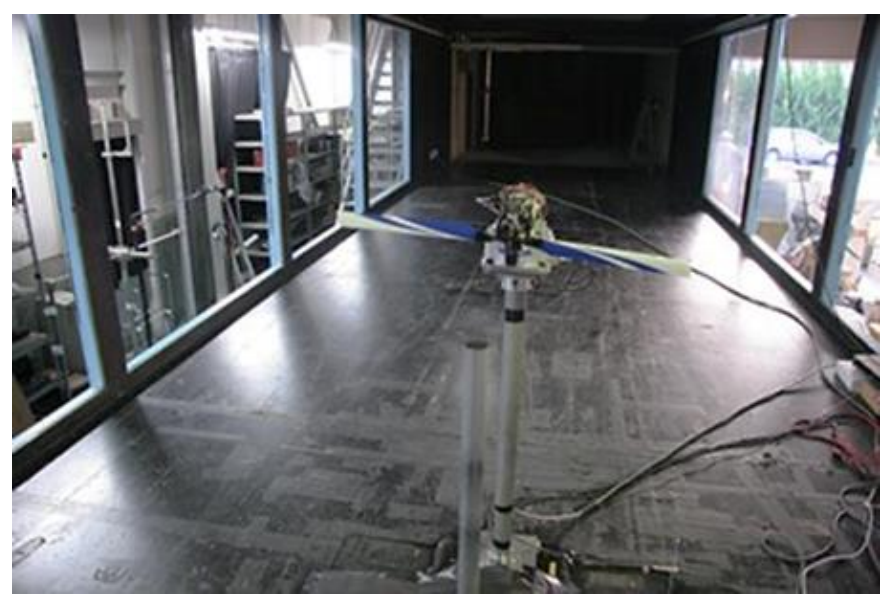

Figure 4. Test model and dummy tower installed in the wind tunnel.

\subsection{Measurement}

- $\quad$ Rotor speed: Magnetic encoder

- $\quad$ Load (top of the tower): 6-axis Load Cell (Nissho)

- $\quad$ Pressure on the dummy tower $(50 \% R, 80 \% R, 8$ points each): Pressure sensor (Otegiken)

\subsection{Test Conditions}

- $\quad$ Wind speed $\left(U_{0}\right): 6 \mathrm{~m} / \mathrm{s}$ (uniform, steady)

- $\quad$ Yaw angle: $0 \mathrm{deg}$

- $\quad$ Blade pitch angle $(\theta): 4,6,8 \mathrm{deg}$

- $\quad$ Tip speed ratio $(\lambda): 6.6-9.2$

\subsection{Test Results}

The measurements for the power coefficient $C_{P}$ and the thrust coefficient $C_{T}$ for the isolated rotor model are shown in Figure 5. The rotor torque was calculated from the rolling moment at the top of the tower. The value of thrust force at the top of the tower was used as the rotor thrust. The maximum value of $C_{P}$ was noted at approximately $\lambda=8$ and $\theta=6 \mathrm{deg}$. However, $C_{T}$ tended to increase with an increase in the tip speed ratio or a decrease in the pitch angle.
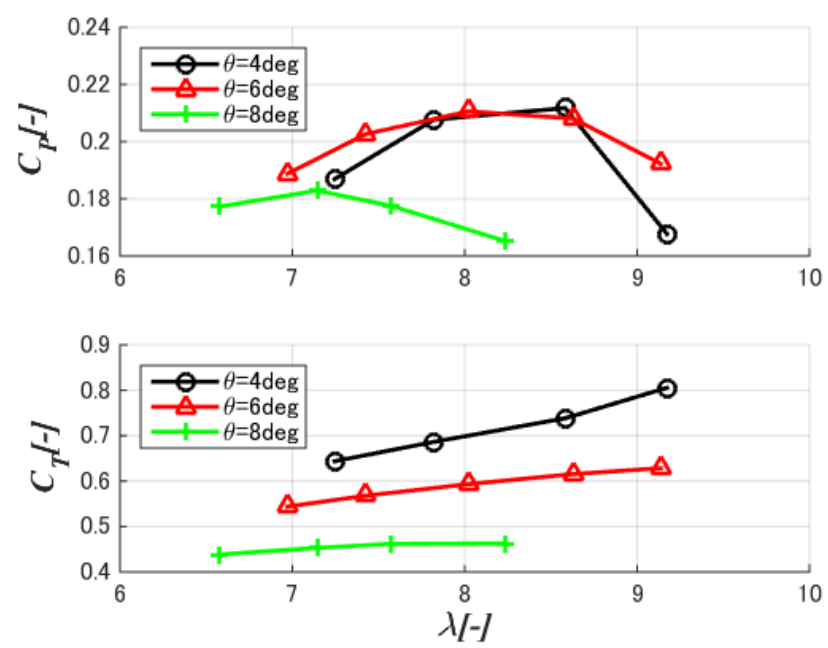

Figure 5. Relationship between the power $\left(C_{P}\right)$ and thrust $\left(C_{T}\right)$ coefficients and the tip speed ratio. $\theta$, blade pitch angle. 
The pressure distributions on the dummy tower in typical cases are shown in Figure 6. Here, 0 deg indicates the upwind side of the tower. The pressure on the $50 \% R$ was relatively higher than that at $80 \% R$. In general, the pressures around the downwind side of the tower $(180 \mathrm{deg})$ tended to be higher as the rotor thrust was larger.

The details of other characteristics are discussed in Section 5.

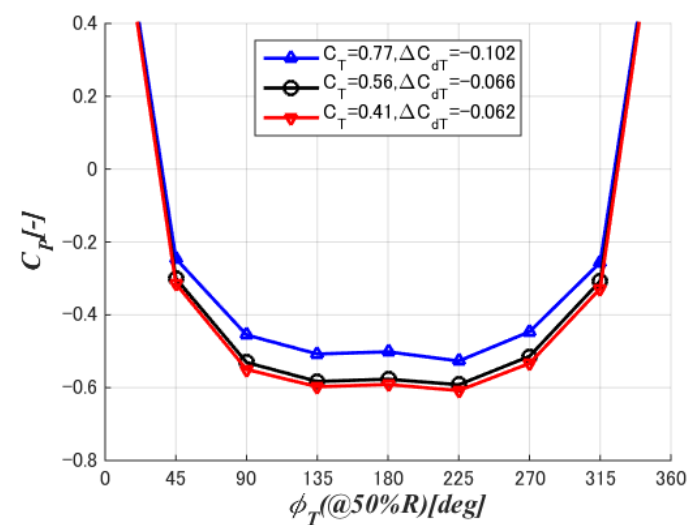

(a) $-6 D_{T}, 50 \% R$

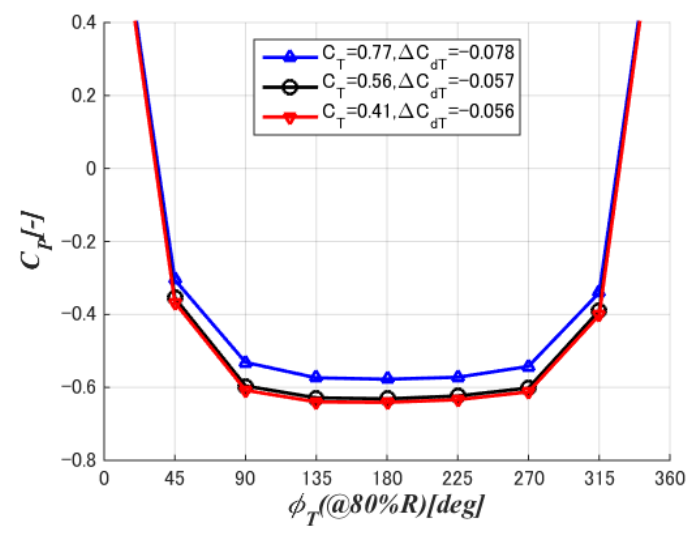

(c) $-6 D_{T}, 80 \% R$

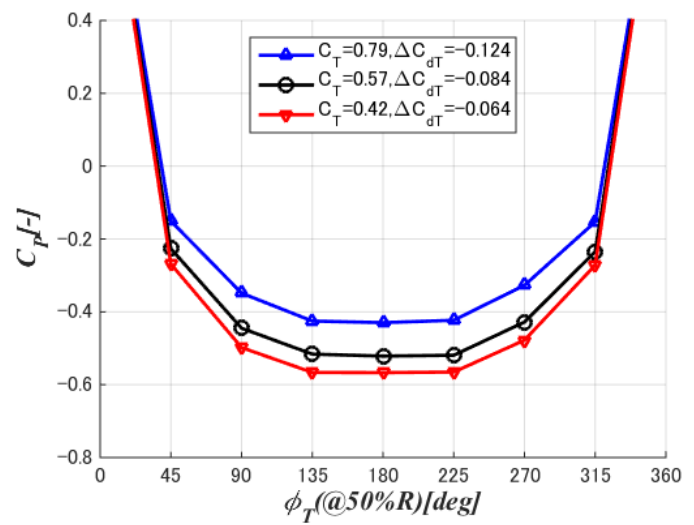

(b) $-4 D_{T}, 50 \% R$

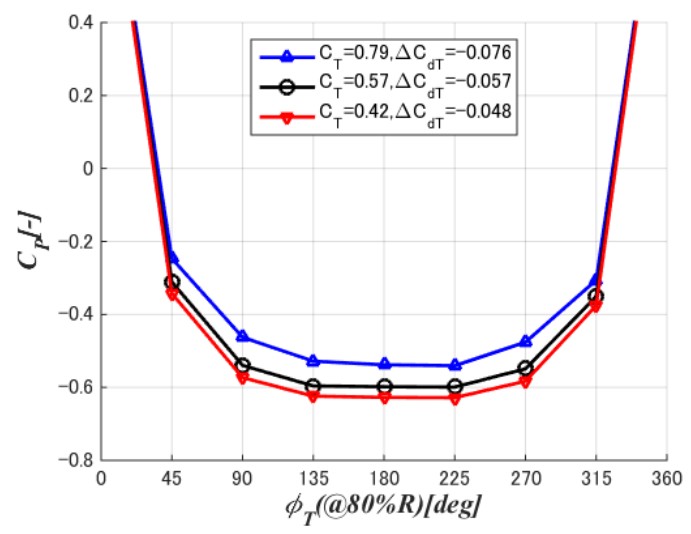

(d) $-4 D_{T}, 80 \% R$

Figure 6. Distribution of the pressure coefficient on the dummy tower in typical cases.

\section{Analysis}

\subsection{Outline}

The relationship between the rotor thrust and the tower drag coefficient was determined by the proposed method described in Section 2. The model is generally the same as the one described in Section 3.3; however, the influence of the support was neglected as the support was located far downwind of the rotor, and this distance was fairly large compared to the support's diameter. In addition, the influence of the nacelle was neglected, as it does not affect the outboard sections, as discussed in this study.

\subsection{CFD Outline}

A CFD analysis was conducted for the rotor using ANSYS CFX [19] considering the k- $\omega$ SST turbulence model. The rotor was modeled by an ADM with uniform load distribution.

The simulation domain and the boundary conditions are summarized in Table 2. The model consisted of structured cells around the ADM with $y+$ is about 1 and unstructured ones otherwise. The total number of cells was approximately 50 million. The typical cells are shown in Figures 7 and 8 . 
Table 2. Simulation domain and boundary conditions.

\begin{tabular}{ccc}
\hline Boundary & Distance from the Rotor Center & Boundary Condition \\
\hline Rotor & $-D / 140 \sim+D / 140$ & ADM \\
Tower & Not available & Not available \\
Inlet & $-4 D$ & Wind speed (uniform) \\
Outlet & $+5 D$ & Ambient pressure \\
Bottom & $-2 D$ & Slip \\
Top & $+2 D$ & Slip \\
Side & $-2 D,+2 D$ & Slip \\
\hline
\end{tabular}

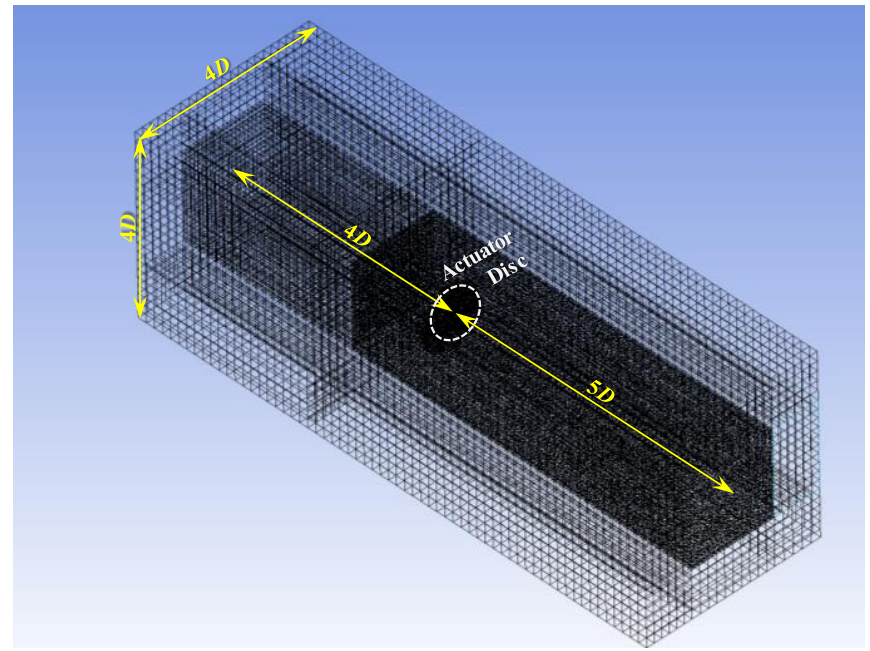

Figure 7. CFD domain.

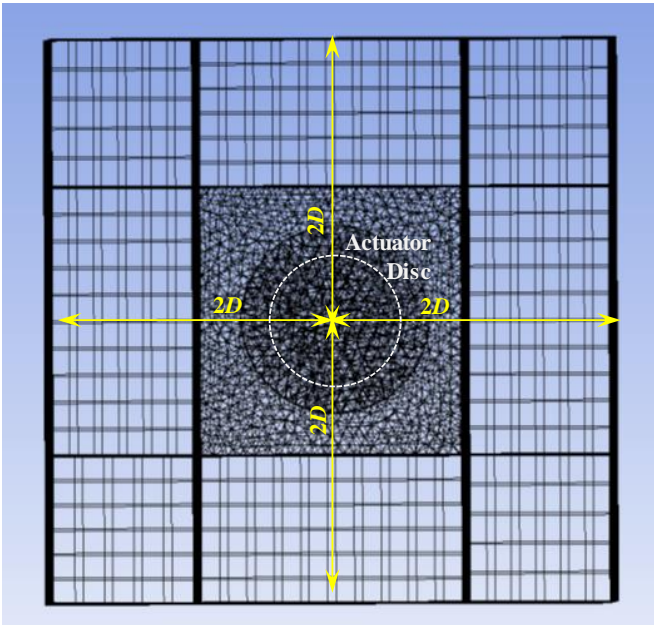

Figure 8. Cells around the rotor.

\subsection{Analysis Conditions}

- Wind speed $\left(U_{0}\right): 6 \mathrm{~m} / \mathrm{s}$ (uniform, steady)

- Yaw angle: 0 deg

- $\quad$ Thrust coefficient $\left(C_{T}\right): 0.4-0.9$ (each 1.0) 


\subsection{Wind Speed Distributions in Front of the Rotor}

The wind speed distributions in typical conditions, $C_{T}=0.4$ and 0.9 , are shown in Figures 9 and 10. The circles in these figures denote the positions of the dummy towers at $-6 D_{T}$ and $-4 D_{T}$. The wind speed tended to decrease in front of the tower in general, and the wind speed was lower in the vicinity of the rotor. A comparison between the two conditions shows that the wind speed around the dummy tower decreased as $C_{T}$ increased. A comparison between the two sections shows that the wind speed in front of the rotor was lower at $50 \% R$ compared to that at $80 \% R$. The load was uniform on the rotor, and the inboard sections were considerably affected by the rotor.

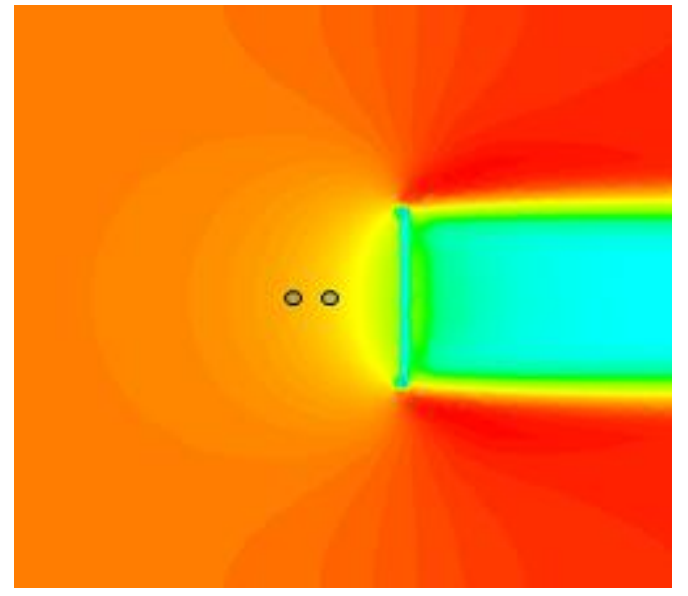

(a) $50 \% R$

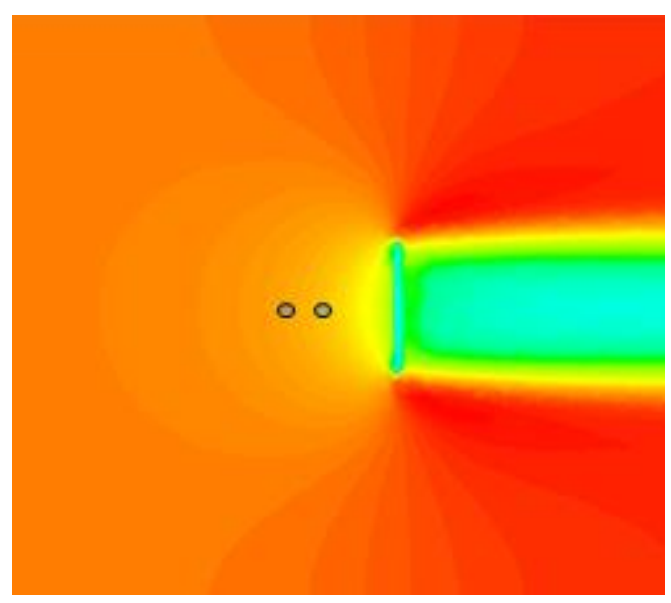

(b) $80 \% R$

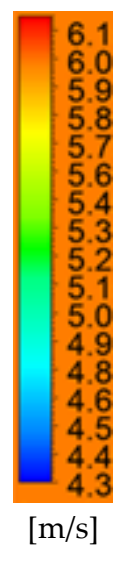

$[\mathrm{m} / \mathrm{s}]$

Figure 9. Wind speed distribution in front of the rotor at $C_{T}=0.4, U_{0}=6 \mathrm{~m} / \mathrm{s}$. (The circles indicate the dummy tower positions at $-6 D_{T}$ and $-4 D_{T}$ ).

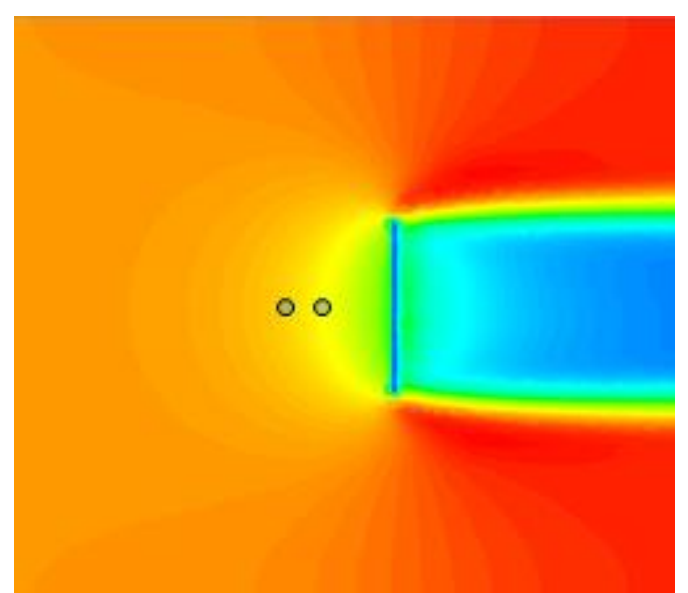

(a) $50 \% R$

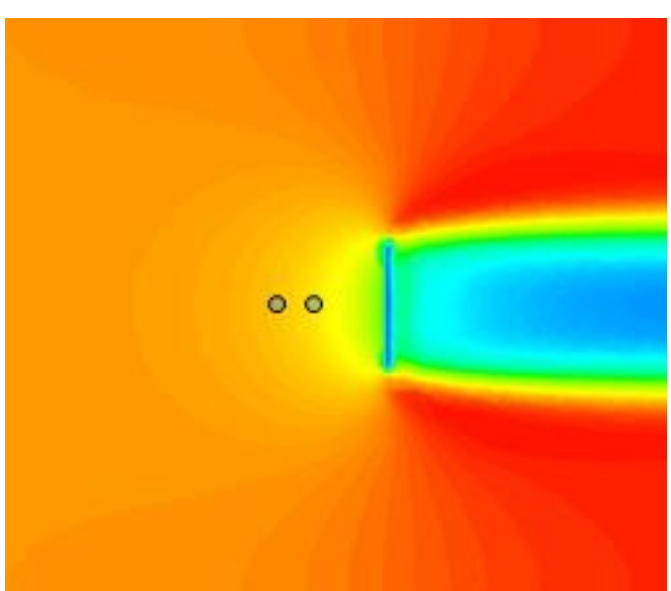

(b) $80 \% R$

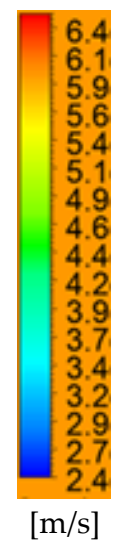

$[\mathrm{m} / \mathrm{s}]$

Figure 10. Wind speed distribution in front of the rotor at $C_{T}=0.9, U_{0}=6 \mathrm{~m} / \mathrm{s}$. (The circles indicate the dummy tower positions at $-6 D_{T}$ and $-4 D_{T}$ ).

The distributions of the normalized wind speed $\mu_{T}$ and its differential $\partial \mu_{T} / \partial \xi_{T}$ with respect to the normalized distance $\xi_{T}$ in front of the rotor are shown in Figures 11 and 12. The distributions at $C_{T}=0.4$ and 0.9 were identical to those in Figures 9 and 10 in the symmetrical plane. The top subplots correspond to the distributions at $50 \% R$, and the bottom ones correspond to those at $80 \% R$. The wind speed was lower in the vicinity of the rotor and decreased as the thrust coefficient increased, as mentioned above. 

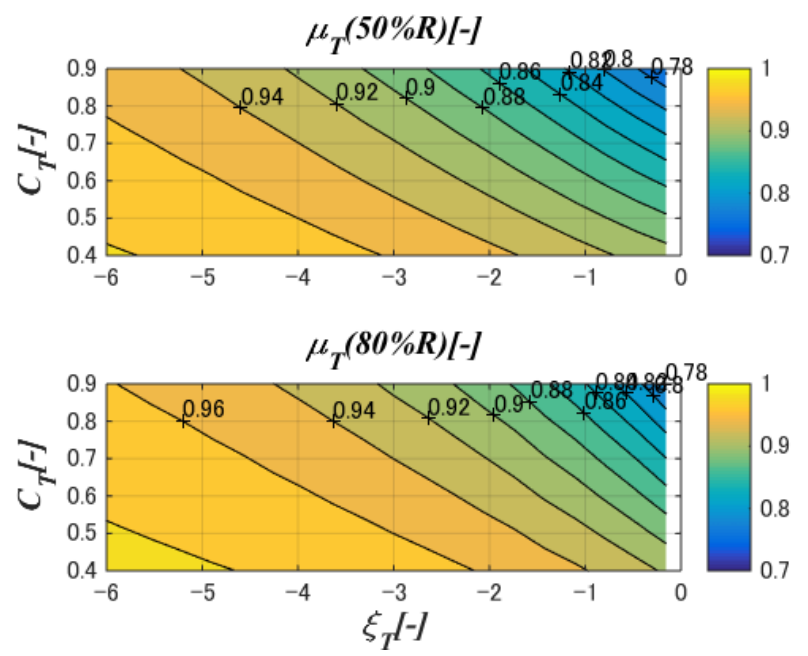

Figure 11. Wind speed in front of the rotor as obtained by CFD. $\mu_{T}$, normalized wind speed, $\xi_{T}$, normalized distance.
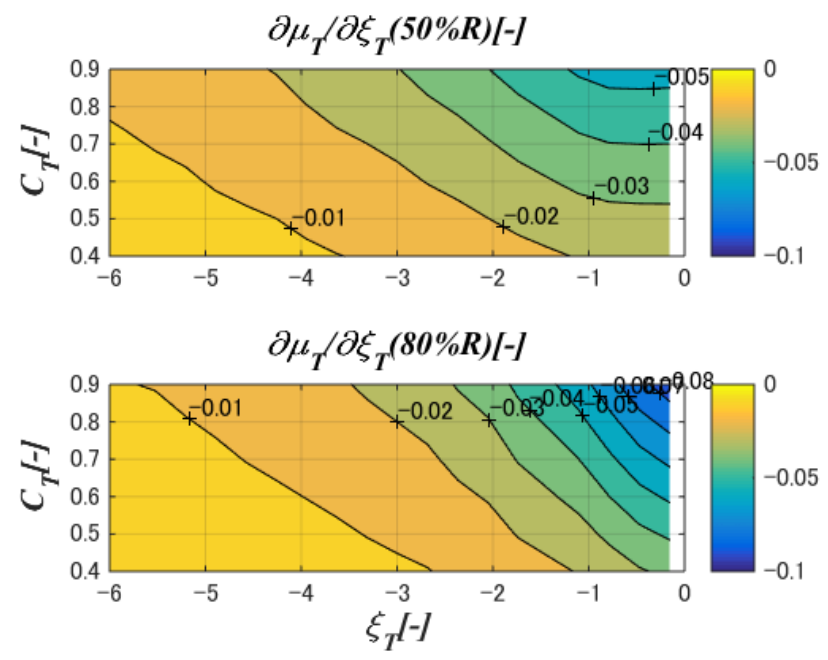

Figure 12. Spatial differential of wind speed in front of the rotor $\left(\partial \mu_{T} / \partial \xi_{T}\right)$ as obtained by CFD.

\subsection{Drag Coefficients of the Virtual Tower}

The deviation of the drag coefficient of the virtual tower calculated by the present theory is shown in Figure 13. The $x$-axis denotes the virtual tower position, and the $y$-axis denotes the thrust coefficient. The diameter of the tower $D_{T}$ was assumed to be $64 \mathrm{~mm}$, as in the experiment. As indicated by Figures 11 and 12, the drag coefficient tended to be smaller as the rotor-tower clearance decreased and the thrust coefficient increased. The drag tended to be smaller at $50 \% R$ than at $80 \% R$.

As shown in Equation (14), the rotor thrust-induced tower drag deviation consisted of the wind speed term and the pressure gradient term. Figure 14 shows the share of the wind speed term to the total deviation. It indicates that approximately $80 \%$ of the change in the drag wss caused by the first term of Equation (12), i.e., the decrease in the wind speed, rather than the pressure gradient. 

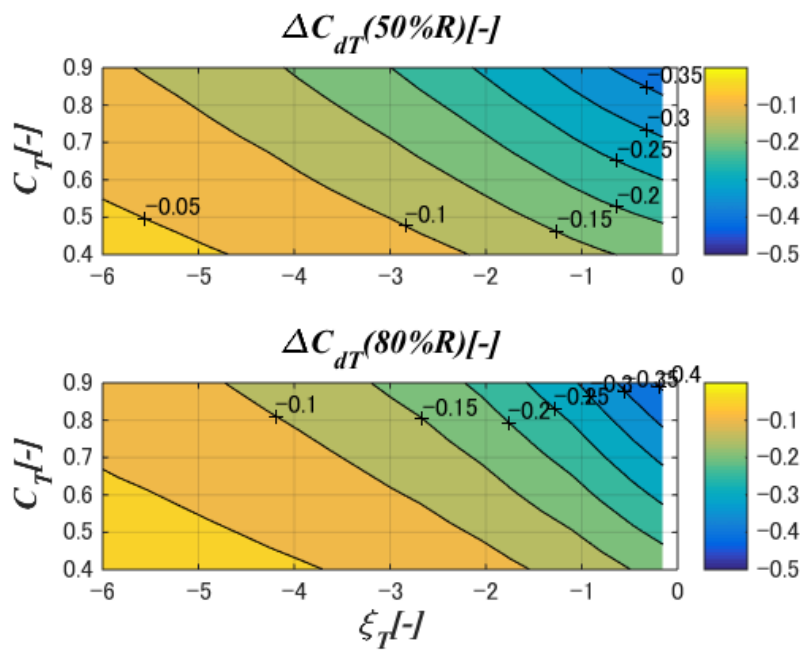

Figure 13. Relationship between the tower section drag and rotor thrust and the virtual tower position. $\Delta C_{d T}$, drag coefficient.
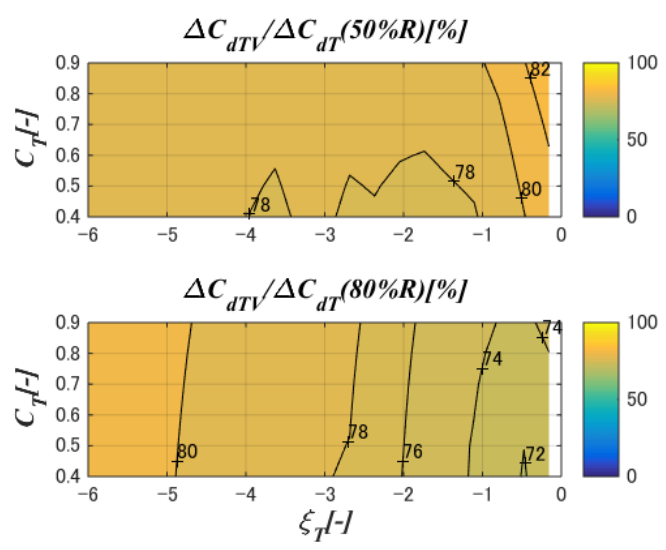

(a) Share of wind speed term $C_{d T V}$.
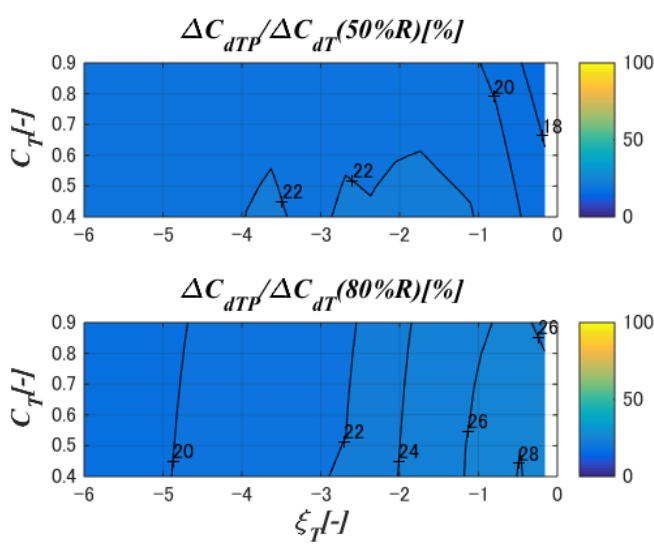

(b) Share of pressure gradient term $C_{d T P}$.

Figure 14. Share of the wind speed term $C_{d T V}$ in the total $C_{d T}$ tower section drag coefficient.

\section{Validation}

The thrust-induced drag deviations $\Delta C_{d T}$ to the thrust coefficient at $-6 D_{T}$ and $-4 D_{T}$ are shown in Figure 15. The lines are approximations for which the intercepts are at $\Delta C_{d T}=0$ and $C_{T}=0$ by definition. The $\Delta C_{d T}$ values for all the cases are shown to be almost proportional to $C_{T}$. The proportion factors are summarized in Table 3. The factors of the former BEM are zero, as the method does not consider the influence of the rotor thrust on the tower drag. On the other hand, the proposed method shows good agreement with the test. The drag coefficients tended to decrease as the rotor thrust increased. The drag coefficient at the $50 \% R$ section was smaller than at the $80 \% R$ section. Further, the drag coefficient decreased as the tower was placed closer to the rotor. 

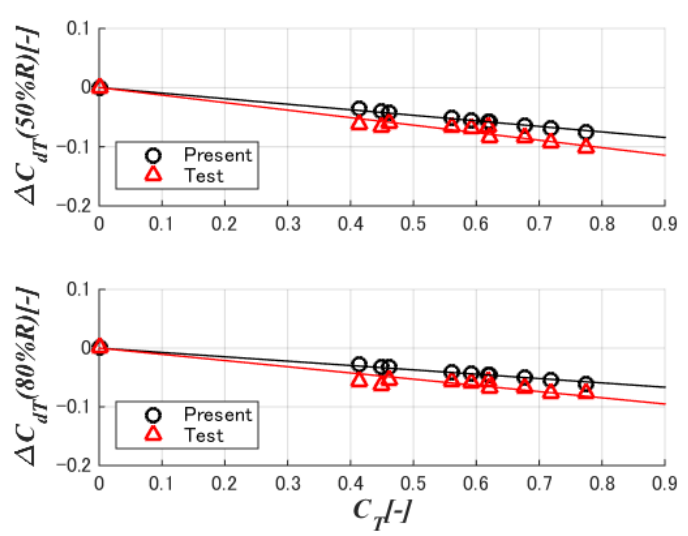

(a) $-6 D_{T}$.
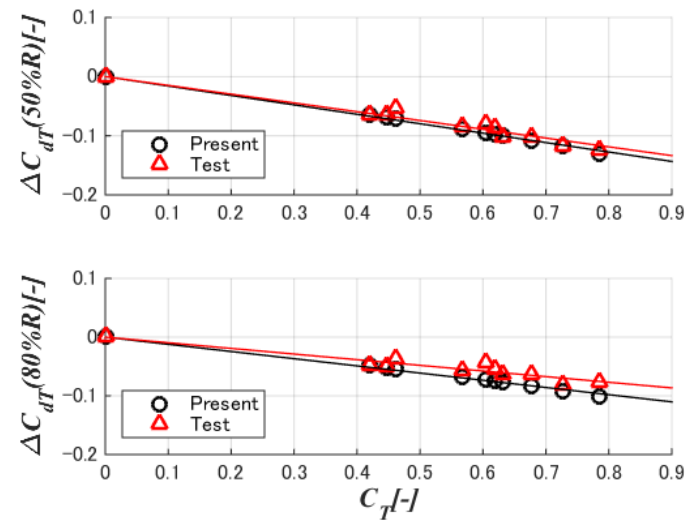

(b) $-4 D_{T}$

Figure 15. Relationship between tower drag and rotor thrust.

Table 3. Fraction of the deviation of the tower drag coefficient to the thrust coefficient.

\begin{tabular}{ccccc}
\hline \multirow{2}{*}{ Dummy Tower Position } & \multirow{2}{*}{ Tower Section } & \multicolumn{2}{c}{ Test } & \multicolumn{2}{c}{ Present } \\
\cline { 3 - 5 } & & $\Delta \boldsymbol{C}_{\boldsymbol{d}} / \boldsymbol{C}_{\boldsymbol{T}}[-]$ & $\Delta \boldsymbol{C}_{\boldsymbol{d} T / \boldsymbol{C}_{\boldsymbol{T}}[-]}$ & Deviation from the Test \\
\hline \multirow{2}{*}{$-6 D_{T}$} & $50 \% R$ & -0.1270 & -0.0937 & $-26.2 \%$ \\
& $80 \% R$ & -0.1058 & -0.0741 & $-30.0 \%$ \\
\hline \multirow{2}{*}{$-4 D_{T}$} & $50 \% R$ & -0.1484 & -0.1594 & $+7.4 \%$ \\
& $80 \% R$ & -0.0961 & -0.1225 & $+27.5 \%$ \\
\hline
\end{tabular}

\section{Conclusions}

A novel analysis method to calculate the average tower drag of downwind turbines, which considers the rotor-induced average tower drag coefficient, was developed. It consists of two terms, that is, the decrease in the wind speed and the pressure gradient caused by the rotor thrust. The rotor thrust distribution is assumed to be uniform. The method was validated by a wind tunnel test. Unlike the former blade element momentum (BEM) method, which assumes the tower drag to be constant, the proposed method demonstrates a much better agreement with the wind tunnel test, with an accuracy of up to $30 \%$. The results show that the tower drag decreases proportionally to the rotor thrust. With regard to the sensitivity of the tower drag with respect to the rotor thrust, the following characteristics were noted:

- The drag coefficient was larger in the inboard section $(50 \% R)$ than in the outboard section $(80 \% R)$.

- The drag coefficient decreased as the tower was positioned closer to the rotor.

- Of the two terms influencing the deviation of the tower section drag, the effect of the decrease in wind speed was more dominant in leading to the decrease in the tower section drag.

By preparing the database of the relationship between the rotor thrust coefficient for the wind speed distribution in front of the rotor, the proposed method is expected to improve the accuracy of the load calculation in the BEM.

In future studies, the present model is planned to be extended to variable loads of wind turbine blades in succession.

Author Contributions: S.Y. organized the research, formulation, and validation. K.F. conducted the computational fluid dynamics simulations, and M.H. and A.T. conducted the wind tunnel test.

Funding: The wind tunnel test was conducted with funding from the "Advanced Practical Research and Development of Wind Power Generation/Advanced Practical Development of Wind Turbine Components/ Research on Over 10 MW Class Wind Turbines (Whole Design)" of the New Energy and Industrial Technology Development Organization (NEDO) in 2013-2014. 
Acknowledgments: The authors express gratitude to Keiji Matsushima, Kimihiko Watanabe, and Yuji Ohya for their support for the wind tunnel test. The authors would also like to thank Masataka Motoyama and Omar Ibrahim for their support in the computational fluid dynamics simulation.

Conflicts of Interest: The authors declare no conflicts of interest.

\section{Nomenclature}

$C_{d T} \quad$ Tower drag coefficient

$C_{d T 0} \quad$ Tower drag coefficient with no rotor thrust

$C_{P} \quad$ Power coefficient

$C_{p} \quad$ Pressure coefficient of the tower

$C_{T} \quad$ Thrust coefficient

D Rotor diameter

$D_{T} \quad$ Tower diameter

$f_{X T} \quad$ Tower section drag

$f_{\text {XT0 }} \quad$ Tower section drag with no rotor thrust

$p_{0} \quad$ Free stream pressure

$p_{T} \quad$ Pressure at the tower position

$R \quad$ Rotor radius

$r \quad$ Station radius of the blade element

$T \quad$ Rotor thrust

$U_{0} \quad$ Free stream wind speed

$u_{T} \quad$ Wind speed at the tower position

$w \quad$ Thickness of the actuator disc

$T \quad$ Longitudinal (or windward) position

$C_{d T} \quad$ Deviation of the tower drag coefficient from that of the isolated tower

$\Delta C_{d T P} \quad$ Deviation of the tower drag coefficient by the effect of the pressure gradient

$\Delta C_{d T V} \quad$ Deviation of the tower drag coefficient by the wind speed

$\Delta f_{X T} \quad$ Deviation of the tower section drag from that of the isolated tower

$\Delta f_{X T P} \quad$ Deviation of the tower section drag by the effect of the pressure gradient

$\Delta f_{X T V} \quad$ Deviation of the tower section drag by the wind speed

$\theta \quad$ Blade pitch angle

$\lambda \quad$ Tip speed ratio

$\mu_{T} \quad$ Normalized wind speed at the tower position

$\xi_{T} \quad$ Position normalized by the tower diameter

$\rho \quad$ Air density

$\phi_{T} \quad$ Azimuth position around the tower (0 deg in front, clockwise around the vertical axis)

ADM Actuator disc model

ALM Actuator line model

BEM Blade element momentum (method)

CFD Computational fluid dynamics

\section{References}

1. Gipe, P. Wind Energy Comes of Age; John Wiley and Sons: Chichester, UK, 1995.

2. Wind Turbines_Part 1: Design Requirements; IEC61400-1, Ed. 3; International Electrotechnical Commission: Geneva, Switzerland, 2005.

3. Germanischer Lloyd. Guidelines for the Certifications of Wind Turbines, Edition 2010; Germanischer Lloyd: Hamburg, Germany, 2010.

4. Burton, T.; Jenkins, N.; Srpe, D.; Bossanyi, E. Wind Energy Handbook, 2nd ed.; John Wiley and Sons: Chichester, UK, 2011.

5. Jonkman, J.M.; Buhl, M.L., Jr. FAST User's Guide; NREL/TP-500-38230; NREL: Golden CO, USA, 2005.

6. DNV GL. Bladed, Version 4.7; DNV GL: Bristol, UK, 2016.

7. Zhao, Q.; Sheng, C.; Afjeh, A. Computational aerodynamic analysis of offshore upwind and downwind turbines. J. Aerodyn. 2014, 2014, 860637. [CrossRef] 
8. Zahle, F.; Madsen, H.A.; Sorensen, N.N. Evaluation of Tower Shadow Effects on Various Wind Turbine Concepts. Available online: http:/ / orbit.dtu.dk/files/3550506/ris-r-1698.pdf (accessed on 19 July 2018).

9. Matiz-Chicacausa, A.; Lopez, O.D. Full downwind turbine simulations using actuator line method. Model. Simul. Eng. 2018, 2018, 2536897. [CrossRef]

10. Wang, T.; Coton, F.N. A high resolution tower shadow model for downwind wind turbines. J. Wind Eng. Ind. Aerodyn. 2001, 89, 873-892. [CrossRef]

11. Yoshida, S.; Kiyoki, S. Load equivalent tower shadow modeling for downwind turbines. J. JSME 2007, 37, 1273-1279. [CrossRef]

12. Yoshida, S.; Kiyoki, S. Load equivalent tower shadow modeling. In Proceedings of the European Wind Energy Conference 2007, Milano, Italy, 7-10 May 2007.

13. Nagao, T.; Kato, T.; Shiraishi, T.; Yoshida, S.; Sugino, J. Development of advanced wind turbine systems for remote islands. Wind Eng. 2006, 28, 729-740. [CrossRef]

14. Yoshida, S. Performance of downwind turbines in complex terrains. Wind Eng. 2006, 30, 487-501. [CrossRef]

15. Yoshida, S. Nacelle Yaw Measurement of Downwind Turbines in Complex Terrains; Windtech International: Groningen, The Netherlands, 2008.

16. Saeki, M.; Sano, T.; Kato, H.; Owada, M.; Yoshida, S. Concept of the HITACHI 5MW offshore downwind turbine. In Proceedings of the European Wind Energy Conference 2014, Barcelona, Spain, 10-13 March 2014.

17. Yoshida, S. Combined blade-element momentum-Lifting line model for variable loads of downwind turbine towers. Energies 2018, 11, 2521. [CrossRef]

18. Research Institute of Applied Mechanics, Kyushu University, Boundary Layer Wind Tunnel. Available online: https:/ / www.riam.kyushu-u.ac.jp/windeng/en_equipment.html (accessed on 10 November 2018).

19. ANSYS. ANSYS CFX; ANSYS: Canonsburg, PA, USA, 2006.

(C) 2019 by the authors. Licensee MDPI, Basel, Switzerland. This article is an open access article distributed under the terms and conditions of the Creative Commons Attribution (CC BY) license (http:/ / creativecommons.org/licenses/by/4.0/). 